\begin{tabular}{lllll}
\hline Motrivivência & Ano XX, & No 30, P. 197-216 & Jun./2008 \\
\hline
\end{tabular}

\title{
Etiologia da Orientação Sexual e suas Implicações para a Ciência do Movimento Humano/ Etiologia da Orientação Sexual.
}

\section{Etiology of Sexual Orientation and its Implications to the Kinesis Science/ Etiology of Sexual Orientation}

Fernando Luiz Cardoso'

\begin{abstract}
Resumo
Este artigo discute algumas das muitas contribuições teóricas no campo da etiologia da orientação sexual humana, bem como importantes conceitos e sua articulação com um dos seus extremos - a homossexualidade. Evitou tomar-se a confortável postura politicamente correta ao tentar discutir a orientação sexual humana à luz de uma concepção interativista e fundamentada em dados e evidências e não apenas em conceitos e falácias não-percebidas. O propósito desta discussão foi o de organizar de forma mais objetiva na língua portuguesa, diferentes concepções acadêmicas sobre a etiologia desse fenômeno
\end{abstract}

1 Professor Adjunto do Programa de Pós-Graduação em Ciência do Movimento Humano da Universidade do Estado de Santa Catarina - UDESC. Mestre em Antropologia Social pela UFSC, Mestre em Saúde Pública pelo IASHS (EUA) e Doutor em Sexualidade Humana pelo IASHS (EUA). Contato:d2flc@udesc.br 
e orientar futuras pesquisas de cunho mais explicativo na ciência do movimento humano que terão influencias políticas sobre a percepção da corporeidade.

Palavras Chaves: Homossexualidade; Epistemologia; Gênero; Orientação sexual; Orientação motora. political perception of bodyness.

Keywords: Homosexuality; Epistemology; Gender; Sexual orientation; Motor orientation.

\section{Introdução}

Com base nas atuais evidências científicas ainda sabemos muito pouco sobre a etiologia da orientação sexual; isto é, temos mais hipóteses e dúvidas do que certezas. As atuais explicações variam desde as mais deterministas às mais relativistas, sem falar nas mais políticas e ideológicas. Enfim, são muitas as suposições, mas poucos ainda são os dados ou evidências pautados em criteriosa observação e análise comparativa. Provavelmente muito disto se deve a falta de dialogo e compreensão dos resultados e das implicações das pesquisas comparativas que tentam explicar ao invés de apenas interpretar a orientação sexual humana.

A causa da orientação sexual seja ela homossexualidade ou heterossexualidade, é que esta se desenvolve em fases e é multifatorial. De forma geral, pode-se dizer que os anos formativos mais importantes para homo, bi, e heterossexualidade estão até a fase da

infância, e não como muitos pensam na puberdade e adolescência. Em resumo, os hormônios ativariam na puberdade apenas o que já se formou anteriormente (PILLARD e WEINRICH, 1986; RAHMAN, WILSON e ABRAHAMS, 2003). Porém, esta percepção tão hegemônica na academia brasileira tem que começar a responder as novas evidências científicas que começam a questioná-la pelo menos em parte.

É claro que existem discordantes sobre esta posição psicodesenvolvimentista de Money (PILLARD e WEINRICH, 1986; RAHMAN, WILSON e ABRAHAMS, 2003) sobre a etiologia da orientação sexual. Diamond (1997) que relaciona orientação sexual com o processo biológico de diferenciação sexual, por exemplo, cita inúmeras pesquisas experimentais de que o sistema nervoso de animais já está programado para comportar-se como macho ou fêmea a partir do nascimento. Além disso, o autor ainda cita outras pesquisas na psicologia que mostram que o modelo 
social teria um papel menor no desenvolvimento do comportamento sexual tipificado em crianças.

Para melhor tentar explicar e prever a orientação sexual humana, muitas hipóteses tem surgido no mundo acadêmico. Com o objetivo de explicá-las e analisá-las, eu as agrupei em cinco categorias básicas e as denominei de: hipóteses evolucionistas, hipóteses biológicas, hipóteses de identidade, hipóteses de personalidade e hipóteses motoras. Isto não significa que estas devam ser tomadas como categorias estanques, mas sim, como agrupamentos ou classificações que podem se justapor ou se complementarem considerando uma possível natureza "polimorfa" da orientação sexual humana.

Outro aspecto importante a se salientar nesta questão trata-se da visão dicotômica e ingênua de muitos pesquisadores sobre a relação fundante entre natureza e cultura para o antropos humano, onde muitos a interpretam como aspectos dissociáveis e independentes. Isto é, não existem indivíduos ou pessoas sem uma interação e influencia do meio ambiente.

As hipóteses evolucionistas geralmente se estruturam a partir dos seguintes pressupostos que podem ser percebidos como produto da adaptação da espécie: Primeiro em um nível mais concreto, existiriam diferenças genéticas entre homossexuais e heterossexuais determinadas na fecundação do óvulo; Segundo, em um nível mais abstrato existiriam diferenças epigenéticas entre homossexuais e heterossexuais determinadas no processo da ontogênese onde alguns genes podem ter sido ativados ou desativados for influencias do meio. A partir desses pressupostos teóricos os evolucionistas tentam entender como e por que a prática sexual entre pessoas do mesmo sexo é um fenômeno recorrente em todas as sociedades humanas. Considerando que esta prática, a princípio, negaria o principal objetivo da evolução humana: passar genes para o futuro. Mas, sabemos que o sexo tem múltiplas funções entre os animais.

As hipóteses biológicas, que necessariamente não precisam ter preocupações evolucionistas, estão embasadas nos seguintes argumentos: a) a ordem biológica de nascimento poderia influenciar a orientação sexual dos indivíduos (BLANCHARD, 1997; BLANCHARD e BOGAERT, 1996; BLANCHARD e KLASSEN, 1997; BLANCHARD, MCCONKEY, ROPER et al, 1985; ELLIS, HOFFMAN e BURKE, 1990; THOMAS e FRENCH, 1985); b) ter irmãos mais velhos poderia influenciar a orientação sexual dos indivíduos (BLANCHARD e ZUCKER, 1994; 
BLANCHARD e SHERIDAN, 1992); C) demasiado estresse materno na fase intra-uterina poderia influenciar o processo de diferenciação sexual e a posterior orientação sexual dos indivíduos (ELLIS, HOFFMAN e BURKE, 1990; EVANS, 1972); d) fatores genéticos ainda não especificamente determinados poderiam influenciar a orientação sexual dos indivíduos (ALLEN e GORSKI, 1992; BAILEY e MARTIN, 1995; BAILEY, PILLARD, NEALE et al, 1993; BAILEY e PILLARD, 1991; BAILEY e ZUCKER, 1995; DAVENPORT, 1986; FINK, SEYDEL, MANNING et al, 2006; GREEN, 1987; HARRY, 1982; LEWIS e SCHOENFELDT, 1973; MCCONAGHY, BUHRICH e SILOVE, 1994; MEYER-BAHLBURG,1985; PILLARD e WEINRICH, 1986; KIMURA, 1994; KINSEY, POMEROY e MARTIN, 1948; RAHMAN, WILSON e ABRAHAMS, 2003).

As hipóteses da identidade estruturam-se a partir dos seguintes argumentos: a) travestir-se de forma prazerosa ou não na infância poderia prever uma futura orientação sexual (BENTLER, 1976; DIAMOND, 1997; GRELLERT, NEWCOM e BENTLER, 1982; HAMER e COPELAND, 1994; WHITAM, 1980); b) sentir-se mais ou menos feminino na infância poderia prever uma futura orientação sexual (GREEN, 1987); c) um maior ou menor interesse na infância por estética e decoração poderia prever uma futura orientação sexual (DALY, 1993; MONEY, 1986; WHITAM, 1983); d) ter sido percebido como uma criança mais bonitinha do que a media poderia prever uma futura orientação sexual (MANOSEVITZ, 1970; ZUCKER, 1990); e) a avaliação de se possuir uma identidade sexual mais feminina por terceiros poderia prever a orientação sexual (DALY, 1993; MCCONAGHY, BUHRICH e SILOVE, 1994; WERNER, 1979).

Considerando que os poucos estudos longitudinais de comportamento travestilizado na infância correlacionados com a orientação homossexual foram feitos apenas nos EUA, Whitam (WILSON e RAHMAN, 2005) descobriu similares correlações em estudos comparativos transculturais com relação a este assunto. A primeira sugere que existe uma clara relação entre comportamento prazeroso travestilizado já nos primórdios da infância com a orientação homossexual.

As hipóteses de traços específicos sobre a personalidade estruturam-se a partir dos seguintes argumentos: a) ter uma personalidade mais ou menos submissiva na infância poderia prever uma futura orientação sexual (FINK, SEYDEL, MANNING e KAPPELER, 2006; WERNER, 1998); b) ter uma personalidade mais ou menos agressiva 
na infância poderia prever uma futura orientação sexual(CARDOSO, FELIPE e HEDEGAARD, 2005; ZUCKER, WILD, BRADLEY et al, 1993); C) preferência na infância por determinadas profissões poderia prever uma futura orientação sexual (MONEY, 1988); d) ter uma preferência por atividades mais ou menos solitárias na infância poderia prever uma futura orientação sexual (MACDERMID, ZUCKER, BRADLEY et al, 1998); e) evitar mais ou menos brigas físicas na infância poderia prever uma futura orientação sexual (ELLIS, PECKHAM, AMES et al, 1988); f) preferir brincar mais ou menos com as meninas na infância poderia prever uma futura orientação sexual (BAILEY e ZUCKER, 1995; GRELLERT, NEWCOM, e BENTLER, 1982; KEEN, 1992; WHITAM E MATHY, 1986).

As hipóteses sobre comportamento motor estruturam-se a partir dos seguintes argumentos: a) ter uma orientação motora mais direcionada para atividade físicas cíclicas e individuais (andar, correr, nadar, ciclismo) na infância poderia prever uma futura orientação sexual (CARDOSO, 2005; CARDOSO e WERNER, 2004; CARDOSO, 2002, 1996; CHUNG e HARMON, 1994); b) ter mais ou menos interesse em esportes na infância poderia prever uma futura orientação sexual (CARDOSO, 2005; CARDOSO e WERNER, 2004; GRELLERT, NEWCOM E BENTLER, 1982; MCCONAGHY, BUHRICH E SILOVE, 1994; MCCORMICK, WITELSON e KINGSTONE, 1990); c) ter uma orientação espacial similar ao sexo oposto poderia prever uma futura orientação sexual (KINSEY, POMEROY e MARTIN, 1948; SAGHIR e ROBINS, 1973, WOLKE, 2001); d) evitar esportes de embate e contato físico direto uma futura orientação sexual (MCCONAGHY, BUHRICH e SILOVE, 1994; MCCORMICK, WITELSON e KINGSTONE, 1990); e) dançar individualmente desordenadamente ou desinconsadamente e orientação heterossexual em homens como resultado de uma exposição a altos níveis de testosterona (GOTESTAM, 1992).

Estas hipóteses de forma geral estão procurando por comportamentos correlacionadas as orientações sexuais que possa nos dar uma luz para melhor entender a sua etiologia. Considerando que uma correlação entre duas variáveis não implica necessariamente em causalidade, as explicações mais ambiciosas em termos de causalidade e de origem da orientação sexual humana nos vêm da teoria da evolução, apesar do desvio de uma orientação eminentemente heterossexual parecer negar dois princípios fundamentais dessa teoria: o sucesso reprodutivo e a 
sobrevivência ao rigor da seleção natural. No entanto, evidências no campo da teoria da evolução são muito difíceis de produzir.

Muitos teóricos têm considerado apenas o aspecto adaptativo de uma orientação homossexual, mas argumentos evolucionistas devem também dar conta de como as mudanças teriam surgido em nossa historia filogenética. Werner (1979) sugere uma seqüência evolutiva a partir da cooperação entre primatas machos que evoluiu gradualmente dos sistemas de marcação de território em animais mais solitários, para sistemas marcados pela dominação e subordinação em grupos com outros machos, para sistemas marcados pela aliança em sistemas sociais mais complexos. Assim apenas pequenas mudanças seriam necessárias para se mudar de um sistema para o outro e as relações sexuais com indivíduos do mesmo sexo seria uma estratégia de cooperação e construção de alianças. Maiores detalhes sobre a evolução da homossexualidade, favor consultar Cardoso e Werner (2004).

$\mathrm{Na}$ atualidade, a ciência sexológica conta com pesquisas explicativas comparativas infelizmente apenas na área biológica no tocando a orientação sexual, pois outras áreas do conhecimento que lidam com o assunto não conseguem avançar para além dos con- ceitos e posições falaciosas. Esses estudos têm produzido consideráveis evidências que apontam para as influências do processo de diferenciação sexual, aspectos hereditários, assim como, possíveis influências da tecnologia no desenvolvimento e determinação da orientação sexual humana. Mais detalhes sobre essas complexas hipóteses e teorias pode ser lida em Cardoso (1994). Por fim, somente a replicabilidade de correlações sobre semelhanças e diferenças entre homossexuais e heterossexuais podem nos ajudar a melhor entender a etiologia da orientação sexual enquanto um fenômeno único ou ainda enquanto múltiplos fenômenos paralelos que aparecem simultaneamente com aquilo que aqui definimos como orientação sexual - comportamento e/ou fantasia sexual com pessoas do mesmo sexo biológico.

Em resumo as hipóteses biológicas e evolucionistas estão procurando por qualquer tipo de processo biológico relativo ao processo de diferenciação sexual para poder sugerir uma base genética, epigenéticas ou cultural a causa da diferença na orientação sexual humana. Já as hipóteses de identidade, hipóteses de personalidade e hipóteses motoras não desconsideram possíveis influências biológicas, mas estão procurando por fatores ambientais e culturais que possam 
vir a determinar as orientações sexuais ou componentes atrelados a ela. Já as hipóteses evolucionistas estão mais preocupadas em explicar a orientação sexual humana em termos filogenético, isto é, em como um comportamento que a principio que nega a possibilidade da reprodução da espécie, continua presente no comportamento humano ainda hoje.

A partir da revisão de literatura aqui apresentada, a pesquisa comparativa sobre a orientação sexual tem delineado fatores constitutivos de uma identidade típica para os homossexuais em termos de psique, comportamento e corporeidade em diversas sociedades, mas como qualquer fenômeno humano e social, existem exceções intrigantes.

\section{As minorias homossexuais}

Muitos pesquisadores como Bentler (1976), Bell, Weinberg, \& Hammersmith (1981) Cardoso (2005, 2004, 1996, 1994), Davenport (1986), Green (1987), Hockberry \& Billingham (1987), Grellert, Newcom \& Bentler (1994), Meyer-Bahlburg (2000), Zucker (1990) Whitam (1980), dentre outros já mostraram algumas correlações entre um comportamento atípico em termos de conformidade de gênero na infância e uma posterior orientação homossexual ou bis- sexual. No entanto, esses mesmos estudos não deram conta de uma minoria dentre os homossexuais e bissexuais que ao contrário tiveram uma infância típica em relação aos heterossexuais. Como poderíamos tentar responder a isto? Em uma tentativa estruturarei três possíveis explicações para essa intrigante exceção na revisão da literatura.

\section{O suposto argumento de Mo- ney (1988)}

Money provavelmente explicaria estas exceções dentre os homossexuais mais masculinos em termos de gênero, como pessoas que transpassaram a identidade de gênero/papel apenas no critério orientação sexual (homossexualidade/bissexualidade/heterossexualidade), tendo desenvolvido uma típica identidade de gênero nos outros critérios para o seu próprio sexo: diferenciação biológica (macho/intersexual/fêmea) e orientação de gênero (masculino/ andrógino/feminino). Em sua obra Money faz questão de ilustrar tal situação quando cita a situação de atores famosos que possuem todos os requisitos de um galã ou de um símbolo sexual para as mulheres e acabam provocando grande desapontamento social quando chega ao conhecimento do público a sua orientação unilinear homossexual. 
Mas explicar por que alguém se torna homossexual, enquanto outro não, já é algo mais difícil, e Money admite os seus limites teóricos para tal intento.

Mas vale a pena recorrer a algumas conexões que Money sugere, mas não testou, entre a estruturação da identidade de gênero/ papel (IG/P) nos humanos (constituída de sexo biológico, orientação de gênero e orientação sexual) e os comportamentos sexuais atípicos como parte da nossa herança filogenética, denominados por ele de parafílias e que seriam constituintes dos "mapas amorosos" humanos.

Primeiro deve-se esclarecer que homossexualidade para Money não se trata de uma parafílias, pois, os homossexuais, assim como, os heterossexuais conseguem estabelecer relações afetivas com os seus parceiros. Só para lembrar parafílias, em Money, caracteriza a dificuldade de alguém conciliar pelo menos em algumas situações amor e sexo. Parafílico então seria aquele que desconectou por completo a relação amor e tesão do objeto sexual de desejo.

Com o objetivo de buscar explicações causais na filogenia humana para o que ele denominou de parafílias, Money propôs o conceito de "filismo". Alguns filismos cotidianos seriam respirar, tossir, urinar, masturbar, lubrificar, etc. Assim o autor sugere que a base das parafílias humana poderia estar restrita a seis estratégias: o filismo sacrificial/ expiatório: masoquista, o filismo expiatório/sacrificial: sadista, o filismo mercantil/venal, o filismo fetichista / talismático, o filismo estigmático e elegível, e o filismo solicitacional. Estes filismos estariam presentes no ser humano e poderiam ser ativados ou desativados a partir das influências do meio. Talvez alguns desses filismos sugeridos por Money poderiam também ativar uma tendência em alguns casos a transpor a IG/P apenas no critério orientação sexual independentemente do critério gênero e sexo biológico, por exemplo.

Figura I. Transposição de critérios na Identidade de Gênero/ Papel em Money. Criado por Cardoso (2004) Money (1988) propôs o conceito de identidade de gênero/ papel $(I G / P)$ como um conceito englobante, que define o ser a partir de categorias como macho/ fêmea ou intersexo, masculino/ feminino ou andrógino, bissexual ou monossexual (heterossexual ou homossexual), abrangendo um conceito pessoal, social e legal. O autor também incluiu o critério orientação sexual ou o mapa amoroso em seu conceito de identidade de gênero /papel. 
Ano XX, n ${ }^{\circ} 30$, Junho/2008

SEXO

- $\begin{array}{lll} & \\ \text { Macho Intersexuado }\end{array}$

GENERO

$\mathrm{X}$

Masculino

Andrógino

Feminino

ORIENTACAO

$\mathrm{X}$

Heterossexual

Bissexual

Homossexual

\section{$\mathrm{O}$ argumento de Kinsey, Po- meroy \& Martin (1991)}

Kinsey, Pomeroy \& Martin (1991) sugeriria que a homossexualidade trata-se de uma questão de contínuo que articularia sexo biológico, orientação gênero e orientação sexual, ou seja, outros aspectos da personalidade iriam juntos com a orientação sexual. Para o autor, existiriam poucos homossexuais e heterossexuais nos extremos da "Escala Kinsey" em termos de prática, orientação e identidade sexual, por exemplo, estando a maioria das pessoas situadas entre os dois extremos. Os que estão mais próximos do extremo homossexual passam a ser denominado de homossexuais, enquanto os que estão mais próximos do outro extremo como heterossexuais e os mais próximos do centro de bissexuais, que também seriam poucos em números absolutos. Assim os limites da expressão sexual de cada indivíduo estariam relacionados à posição de cada um nesse continuo e aos valores culturais de onde se está inserido. Para o autor, esse contínuo poderia explicar porque alguns supostos homossexuais teriam uma orientação de gênero (masculino/ andrógeno/feminino) mais próxima ou distante do outro sexo biológico, onde os supostos homossexuais com uma infância típica em termos de gênero estariam mais próximos do meio da escala.

Figura II. Continuo da orientação Sexual em Kinsey, Pomeroy \& Martin (1948), Criado por Cardoso (1996). A escala mais importante criada nos últimos anos foi proposta por Kinsey, Pomeroy \& Martin (1948) em seus famosos relatórios sobre o comportamento sexual do homem e da mulher. Os autores propuseram uma escala bipolar que permite uma graduação contínua entre pessoas "exclusivamente heterossexuais" e "exclusivamente homossexuais", considerando ambos os aspectos de orientação sexual: comportamento sexual (prática sexual) e fantasia sexual (orientação sexual). Segundo os 
autores, essa escala deve ser usada em dois momentos, acompanhada das seguintes perguntas: Quais são os seus comportamentos sexuais?

Quais são as suas fantasias sexuais?

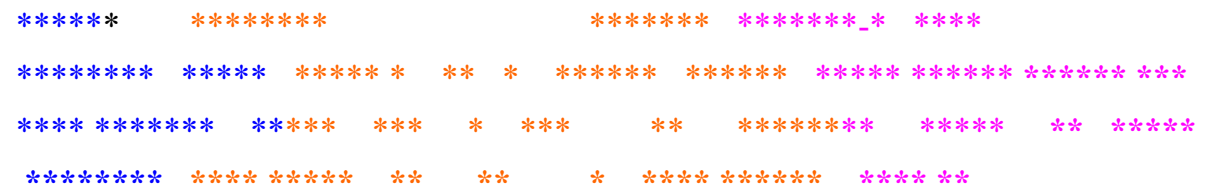

Heterossexualidade

Bissexualidade

Homossexualidade

\section{O argumento de Werner (1998)}

Para Werner (1998) estas exceções no comportamento de homossexuais teriam sido produzidas a partir de uma questão de critério distorcido do qual se estaria utilizando para discriminar e prever o posterior comportamento homossexual. Para o autor, não seria o nível de congruência de gênero e nem o nível de identidade com os estereótipos de gênero, por exemplo, que possibilitaria uma futura previsão da orientação homossexual, mais sim, o fato destes meninos terem sido mais ou menos violentos ou dominantes ou de terem participado ou evitado brigas corporais com os seus colegas. Assim para Werner, o critério ter evitado brigas corporais com colegas do mesmo sexo seria um aspecto que melhor iria predizer uma futura orientação homossexual. O autor justifica esta possível explicação, a partir de trabalhos teóricos anteriores que discutem a etiologia da homossexualidade sob uma perspectiva evolucionista a partir das relações de hierarquia nas sociedades hominídeas e humanas.

Figura III. Comportamento violento na Infância em Werner. Construído por Cardoso (2004).

Werner ao longo de sua carreira vem construindo uma teoria para explicar a origem filogenética da homossexualidade no homo sapiens. Ele parte do principio de que as praticas sexuais entre pessoas do mesmo sexo estariam ligadas a um sistema social de cooperação e criação de alianças entre indivíduos. Assim práticas homossexuais entre macacos Bonobos são e entre guerreiros espartanos eram muitos bem vistas e incentivadas 
socialmente. O que seria socialmente bem visto, nos primórdios da humanidade passaria a ser visto como tabu em algumas sociedades que passam a valorizar as competências individuais em detrimento das relações clientelistas. $\mathrm{O}$ autor esta sugerindo que indivíduos com menores interesses de liderança e poder estariam menos preocupados em adquirir estatus de dominância sobre os outros e seriam mais pronos a desenvolver uma identidade homossexual (1998)

\begin{tabular}{lrr}
\hline Brigou na infância & Evitou brigas \\
\hline Heterossexualidade & Bissexualidade & Homossexualidade
\end{tabular}

Implicações para a ciência do movimento humano

Muitas vezes no mundo acadêmico, incursões teóricas que tentam explicar a variação e a causalidade do comportamento humano, não são vistas com bons olhos devido as possíveis decorrências e implicações políticas para as minorias em termos de sexo, gênero, idade e etnicidade. Ressalto aqui o depoimento de uma aluna em sala de aula quando relatou que o grupo de pesquisa na qual trabalhava, encontrou diferenças significativas entre brancos e negros em termos de desenvolvimento e aprendizagem, porém o grupo decidiu por não tocar nesta questão. Tal receio torna-se compreensível quando nos recordamos do mau uso da ciência em nossa sociedade.

Como uma tentativa ingênua de proteger estas minorias, por vezes acadêmicos se apegam a falácias culturalistas - confundindo o que é com o que deve ser - para relativizar os comportamentos atípicos como forma de evitar interpretações preconceituosas da diferença descrita e apontada cientificamente.

Na minha opinião a melhor saída para deixar os dados falarem por si só seria a adoção no meio acadêmico de uma postura política de reconhecimento e valorização da diferença, seja ela de ordem biológi$\mathrm{ca}$, social ou cultural. Salientando que possíveis diferenças encontradas dentro e entre grupos, caracterizam-se como variação e riqueza da espécie humana onde não se pode admitir qualquer tipo de julgamento moral que as categorizem enquanto anormalidade ou doença que precisaria ser corrigida ou tratada.

Por exemplo, nas minhas pesquisas comparativas de campo sobre o desenvolvimento humano 
tenho colecionado evidencias sobre a correlação entre orientação sexual e a preferência por algumas atividades motoras e esportivas (CARDOSO, FELIPE e HEDEGAARD, 2005; CARDOSO, 2005, 2002, 1994). Esse delineamento comportamental que eu denominei de orientação motora tem ajudado em muito a minha compreensão sobre os tradicionais conflitos de sexo e gênero nas aulas de Educação Física que não são trabalhados pela omissão do corpo docente que não sabe como agir ou intervir. Ao discriminar uma orientação motora/esportiva para uma minoria, por exemplo, homossexuais, não tenho interesse em marginalizálos, mas sim, garanti-los o direito de escolha as atividades lúdicas e esportivas geralmente planejadas a partir da tradicional diferença estereotipada entre meninos e meninas. Assim, quando diferenciamos distintos grupos e suas preferências/ habilidades passamos a ter mais condições de promover um projeto co-educativo de fato que assuma as diferenças e promova a inclusão sem julgamento.

\section{Orientação sexual verso orien- tação motora na educação física inclusiva}

Caso a posterior orientação homossexual tenha relação com a identidade de gênero cruzada na infância, talvez possamos começar a falar sobre um outro critério que estaria atrelado a identidade de gênero/papel: a orientação motora. Pôr orientação motora entendo, a tendência em termos de potencialidade que as pessoas têm para determinados tipos de atividades motoras. As atividades físicas podem ter diferentes naturezas, algumas delas podem ter características únicas, outras características mais diversificadas. Mas quase todas podem ser descritas e classificadas a partir de alguns detalhes básicos como, por exemplo, quanto à natureza da atividade em mais ou menos organizadas e complexas, e quanto ao tipo de interação que pode ser com um grupo ou consigo mesmo.

Assim as pessoas têm diferentes preferências por atividades físicas e jogos de forma geral. Algumas preferem atividades de alta organização como a natação e o ciclismo pôr exemplo, já outras preferem atividades de alta complexidade como o futebol e a ginástica. Alguns preferem atividades coletivas como o basquetebol e o voleibol, enquanto outras atividades individuais como saltos ornamentais ou esportes de combate.

No aspecto educacional, professores de Educação Física têm um íntimo contato com muitas destas diferentes expressões corporais das múltiplas identidades de gênero, 
assim como também um íntimo contato com os conflitos decorrentes destas relações que acontecem entre individuo e expectativas sociais. Para estes profissionais de forma geral, não é difícil identificar a orientação motora de seus alunos, uma vez que estes têm uma formação e experiência sobre motricidade humana e as atividades esportivas típicas da modernidade. Muitos dos grandes nomes esportivos foram identificados em turmas de Educação Física escolares e passaram a se dedicar ao treinamento esportivo a partir do olho clínico, da indicação e do estímulo de seus professores.

Como qualquer manifestação social, as atividades esportivas surgiram e evoluíram respeitando as supostas diferenças biológicas entre homens e mulheres. Assim temos esportes que surgiram como práticas eminentemente masculinas ou femininas. O que se percebe nesse contexto, apesar das mulheres estarem cada vez mais tomando parte em esportes mais masculinos é que em média homens e mulheres diferem em termos de preferência e habilidade por atividades esportivas.

Segundo testes realizados com ambos os sexos por Kimura (1994) as mulheres diferem dos homens por ter maior precisão nas tarefas que necessitam de coordenação motora fina. Já os homens se sobressaem em certas tarefas que exigem maior organização espacial, como lançamento direcionado.

Thomas \& Thomas (1988) avaliaram as diferenças de gênero comparando desempenho motor, atividades motoras, atividade física e saúdes relacionadas à aptidão física. A diferença de gênero no desempenho motor foi percebida entre idade e 12 das 20 tarefas testadas, o que resultou em três diferentes tipos de curvas. A maioria das diferenças é sugerida como sendo ambientalmente induzidas antes da puberdade, sendo as outras de influência interativas entre biologia e ambiente depois da puberdade. O nível de atividade motora é mais alto em meninos até mesmo na infância, e as diferenças de gênero aumentaram da infância á adolescência. Isto sugere que a hereditariedade influencia a diferença inicialmente, mas interage com as circunstâncias ambientais assim que as crianças crescem e se desenvolvem. Garotos de vários países foram observados como sendo mais fisicamente ativos do que as meninas, o que justificaria um melhor desempenho em testes de aptidão física em relação às estas.

Thomas \& French (1985) acreditam que as diferenças de gênero anteriores à puberdade em 15 das 20 tarefas (agilidade, tempo de antecipação, queda de braço, equilíbrio, colisão, força de aperto, 
coordenação óculo-motora, flexibilidade, salto à distância, perseguição, tempo de reação, transporte em corrida, sentar-levantar, bater, salto vertical) estudadas são ambientalmente induzidas. Se existe um fator diferencial neste assunto entre meninos e meninas, é que os meninos são envolvidos em jogos mais competitivos do que as meninas e geralmente participam em jogos de maior duração.

O que se está aqui sugerindo é que, se existem diferenças entre machos e fêmeas em termos de potencialidade, capacidade e habilidade motora, logo poderiam existir também diferenças entre pessoas do mesmo sexo com diferentes orientações sexuais. Assim homossexuais homens, por exemplo, teriam potencialidades, capacidades e habilidades motoras mais comuns as mulheres heterossexuais. Esta abordagem ainda muito recente carece de mais dados sobre essa possível correlação. Mas alguns estudos já apontam nessa direção.

Blanchard, Dickey, \& Jones (1995) compararam a desordem de gênero entre homossexuais e não homossexuais homens e descobriu que os homossexuais eram mais baixos e leves em relação ao seu peso médio.

Saghir \& Robins (1973) perceberam que a maioria dos homossexuais estudada não tinha interesse em acompanhar ou participar dos esportes nacionais como o futebol e o beisebol, além de serem mais interessados em esportes sem contato corporal, como natação, esqui, ou tênis. Dois terços dos homens heterossexuais tinham interesse em esportes coletivos, enquanto apenas $10 \%$ dos homossexuais reportaram tal interesse. Os homossexuais também declararam maior interesse nas modalidades esportivas mais artísticas do que os heterossexuais.

Bell, Weinberg \& Hammersmith (1981) analisaram uma amostragem de 575 homens homossexuais brancos em relação a um grupo controle de 284 heterossexuais brancos em são Francisco (USA). Eles perceberam muitas diferenças entre os dois grupos em relação a suas preferências por atividades na infância, por exemplo, poucos homossexuais falaram gostar de atividades esportivas como beisebol e futebol. Harry (1982) em um estudo realizado em Chicago usou uma amostragem maior do que a de Bell, Weinberg \& Hammersmith (1981)e encontrou similares diferenças entre homossexuais e heterossexuais em relação à orientação esportiva.

Whitam \& Marthy (1986) que realizaram uma pesquisa transcultural entre Brasil, Filipinas e Estados Unidos perceberam as mesmas correlações entre ser homossexual e 
preferir atividades esportivas leves, assim como ser heterossexual e preferir atividades esportivas pesadas nestas três distintas realidades culturais.

No entanto, ainda necessitamos de mais estudos específicos que encontrem correlações mais precisas entre orientação esportiva ou motora com a orientação homo, bi e heterossexual em outras sociedades. Apesar de Cardoso (2002) tê-las encontrado em três realidades culturais distintas: Brasil, Turquia e Tailândia onde se controlou também a classe social.

\section{Considerações finais}

A ciência positiva, veementemente criticada em alguns setores acadêmicos, quando cercada desses cuidados pode produzir contribuições úteis para as ciências humanas e da educação no sentido de organizar, testar e selecionar os melhores argumentos e explicações para a diversidade de comportamentos no tocante ao comportamento sexual e motor humano. Ao produzir análises mais claras e objetivas transforma-se também em um importante instrumento político para garantir a igualdade de direitos em uma sociedade que não assume a sua própria diversidade. Enfim, sugere-se aqui que distinguir e discriminar metodologicamente para estudar e entender, sem marginalizar possíveis diferenças, trata-se de uma eficaz estratégia metodológica para a pesquisa. Ao se distinguir e discriminar para melhor se conhecer pode-se também lutar por garantias de direitos iguais a essas minorias invisíveis socialmente. Porque ninguém defende aquilo que não conhece.

\section{Referências}

ALLEN, L. \& GORSKI, R. Sexual orientation and the size of the anterior commissure in the human brain. Proceedings of the National Academy of Sciences, 89, 7199-7202, 1992.

BAILEY, M. \& MARTIN, N. A twin registry study of sexual orientation. Paper presented at the $21^{\text {st }}$ Annual Meeting of International Academy of sex research. Provincetown (MA), 1995, September.

BAILEY, M. \& ZUCKER, K. Childhood sex-typed behavior and sexual orientation: A conceptual analyses and quantitative review. Developmental Psychology, 31, 43-55, 1995.

BAILEY, M., PILLARD, R., NEALE, M., \& AGYEI. Heritable factors influence orientation in women. Archives General Psychiatry, 50, 217-223, 1993.

BAILEY, M. \& PILLARD, R. A genetic study of male sexual orientation. 
Archives General Psychiatry, 48, 1089-1096, 1991.

BELL, A., WEINBERG, M. \& HAMMERSMITH, S. Sexual preference: Its development in men and women. Bloomington: Indiana University Press, 1981.

BENTLER, P. A typology of transsexualism: Gender identity theory and data. Archives of Sexual Behavior, 5, 567-584, 1976.

BLANCHARD, R. Birth order and sibling sex ratio in homosexual versus heterosexual males and females. Annual Review of Sex Research, 8, 27-67, 1997.

BLANCHARD R. \& KLASSEN, P. $\mathrm{H}-\mathrm{Y}$ antigen and homosexuality in men. Journal of Theoretical Biology, 185, 373-378, 1997.

BLANCHARD, R. \& BOGAERT, A. Biodemographic comparisons of homosexual and heterosexual men in the Kinsey interview data. Archives of Sexual Behavior, 25, 551-579, 1996.

BLANCHARD, R., DICKEY, R. \& JONES, C. Comparison of height and weight in homosexual versus non-homosexual male gender dysphorics. Archives of Sexual Behavior, 24, 543-554, 1995. BLANCHARD, R. \& ZUCKER, K. Reanalyzes of Bell, Weinberg, and Hammersmith's data on birth order, sibling sex ratio, and parental age in homosexual men.
American Journal of Psychiatry 151, 1375 - 1376, 1994.

BLANCHARD, R. \& SHERIDAN, P. Sibship size, sibling sex ratio, birth order, and parental age in homosexual and nonhomosexual gender dysphorics. Journal of Nervous and Mental Disease, 180, 40-47, 1992.

BLANCHARD, R., MCCONKEY, J., ROPERV.\&STEINERB. Measuring physical aggressiveness in heterosexual, homosexual and transsexual males. Archives of Sexual Behavior, 12, 511-524, 1985.

CARDOSO, F. L., FELIPE, M. L., \& HEDEGAARD, C. Gender divergence in physical education classes. Psicologia: Teoria e Pesquisa, 21 (3), 349-357, 2005.

CARDOSO, F. L. Cultural universals and differences in male homosexuality: The case of a Brazilian fishing village. Archives of Sexual Behavior, 34 (1), 105-111, 2005.

CARDOSO, F. L. \& WERNER, W. D. Homosexuality. Em C. Ember \& M. Ember, (Orgs.), Encyclopedia of sex and gender, (pp.204-215). New Haven: Human Relations Area Files, 2004.

CARDOSO, F. L. "Fishermen" Masculinity and sexuality in a Brazilian fishing community. Sexuality and Culture, 6, 45-72, 2002. 
CARDOSO, F. L. O que é orientação Sexual? São Paulo (SP): Ed. Brasiliense, 1996.

CARDOSO, F. L. O gênero e o movimento humano. Revista Brasileira de Ciências do Esporte, 15 (03), 265- 268, 1994.

CHUNG V. \& HARMON, L. The carrier interests and aspiration of gay men: How sex role orientation is related. Journal of Vocational Behavior, 45, 223239, 1994.

DALY, C. Study of twins suggests lesbianism has a genetic component. The Washington Post, pp. A3, 1993 (March 15).

DAVENPORT, C. A follow-up study of 10 feminine boys. Archives of Sexual Behavior, 15, 511-517, 1986.

DIAMOND, M. Sexual identity and sexual orientation in children with traumatized or ambiguous genitalia. The Journal of Sex Research, 34, 199-211, 1997.

DIAMOND, M. Sexual identity and sex roles. The Humanist, march/ april, 1978.

DORNER, G., GEIER, T., AHRENS, L., \& KRELL, L. Prenatal stress as possible aetiogenetic factor of homosexuality in human males. Endokrinologie, 75, 365-368, 1980.

ELLIS, L., HOFFMAN, H. \& BURKE, D. Sex, sexual orientation and criminal and violent behavior.
Personal and Individual Differences, 11, 1207 - 1212, 1990.

ELLIS, L., PECKHAM, W., AMES, M., \& BURKE, D. Sexual orientation of human offspring may be altered by severe maternal stress during pregnancy. The Journal of Sex Research, 25, 152-157, 1988.

EVANS, R. Physical and biochemical characteristics of homosexual men. Journal of Consulting and Clinical Psychology, 39, 140147, 1972.

FINK, B., SEYDEL, H., MANNING, J. T., \& KAPPELER, P. M. A preliminary investigation of the associations between digit ratio and women's perception of men's dance. Personality and Individual Differences, 42, 381390, 2006.

GOTESTAM, O. Handedness, dyslexia and twinning in homosexual men. International Journal of Neuroscience, 63, 179-186, 1992.

GREEN, R. The sissy boy syndrome and the development of homosexuality. New Haven: Yale University Press, 1987.

GRELLERT, E., NEWCOM, M. \& BENTLER P. Childhood play activities of boys and girls' homosexual and heterosexuals. Archives of Sexual Behavior, 11, 451-477, 1982. 
HAMER, D. \& COPELAND, P. The science of desire: The search for the gay gene and the biology of behavior. New York: Simon \& Shuster, 1994.

HARRY (1982). Gay Children Grown Up: Gender, Culture and Gender Deviance. New York: Praeger, 1982.

HOCKBERRY, L. \& BILLINGHAM, E. Sexual orientation and boyhood gender conformity: development of the boyhood gender conformity scale (BGCS). Archives of Sexual Behavior, 16, 475-487, 1987.

KEEN, L. Twin sister study yields more evidence of a genetic origin. Washington Blade, 1992, October, 23.

KIMURA, D. Body asymmetry and intellectual pattern. Personality and Individual Differences, 17, 53-60, 1994.

KINSEY, A., POMEROY, W. \& MARTIN, C. Sexual behavior in the human male. Philadelphia: Saunders Company, 1948.

LE VAY, S. A difference in hypothalamic structure between heterosexual and homosexual men. Science, 253, 1034-1037, 1991.

LEWIS, M. \& SCHOENFELDT, L. Developmental interest factors associated with homosexuality. Journal of Consulting and Clinical Psychology, 41, 291293, 1973.
MACDERMID, S., ZUCKER, K., BRADLEY, S., \& MAING, D. Effects of physical appearance on masculine trait rating of boys and girls with gender identity disorder. Archives of Sexual Behavior, 27, 253-267, 1998.

MANOSEVITZ, M. Early sexual behavior in adult homosexual and heterosexual males. Journal of Abnormal Psychology, 76, 396-402, 1970.

MCCONAGHY, N., BUHRICH, N., \& SILOVE, D. Opposite sexlinked behaviors and homosexual feelings in the predominantly heterosexual male majority. Archives of Sexual Behavior, 23, 565-577, 1994.

MCCORMICK, C., WITELSON S., \& KINGSTONE, E. Left-handedness in homosexual men and women: Neuroendocrine implications. Psychoneuro Endocrinology, 15, 69-76, 1990.

MEYER-BAHLBURG，H . Introduction of gender identity disorder of childhood. Journal of the American Academy of Child Psychiatry, 24, 681-683, 1985.

MILLER, E. \& ELLIS, L. Sex, sex orientation and occupational preference. Paper presented at the meeting of the International Behavioral Development Symposium on biological bases of sexual orientation, gender identity, and gender-typical behavior, Minot (ND), 2000 (May). 
MONEY, J. Gay, straight and in between. New York: Prometheus Books, 1988.

MONEY, J. Love maps: Clinical concepts of sexual/erotic health and pathology, paraphilia, and gender transposition in childhood, adolescence, and maturity. New York: Irvington Publishers, 1986.

PILLARD, R., \& WEINRICH. J. Evidence of familial nature of male homosexuality. Achieves of General Psychiatry, 43, 808812, 1986.

RAHMAN, Q., WILSON, G., \& ABRAHAMS, S. Sexual orientation related differences in spatial memory. Journal of the International Neuropsychological Society, 9, 376-383, 2003.

SAGHIR, M. T. \& ROBINS, E.. Male and female homosexuality: A comprehensive investigation. Baltimore: Williams \& Wilkins, 1973.

SIEGELMAN, M. Birth order and family size of homosexual men and women. Journal of Consulting and Clinical Psychology, 41, 164, 1973.

THOMAS, J. \& FRENCH, K. Gender differences across age in motor performance: A meta-analyses. Physiological Bulletin, 98(2), 260-282, 1985.

THOMAS, J. \& THOMAS, $\mathrm{K}$. Development of gender differences in physical activity. Quest, 40, 219-229, 1988.

TUTTLE, G. \& PILLARD, R. "Sexual orientation and cognitive abilities". Archives of Sexual Behavior, 20, 307-318, 1991.

WERNER, D.W. Sobre a evolução e variação cultural na homossexualidade masculina. Em J. Pedro \& M. Grossi (Orgs.), Masculino, feminino, plural, (pp. 99-130). Florianópolis: Universidade Federal de Santa Catarina, 1998.

WERNER, D. W. A cross-cultural perspective on theory and research on male homosexuality. Journal of Homosexuality, 4, 345-362, 1979.

WHITAM, F. \& MATHY, R. Male homosexuality in four societies: Brazil, Guatemala, the Philippines and the United States. New York: Westport, Connecticut, 1986.

WHITAM, F. Culturally invariable properties of male homosexuality: tentative conclusions from crosscultural research. Archives of Sexual Behavior, 12, 207- 226, 1983.

WHITAM, F. Childhood predictors of adult homosexuality. Journal of Sexual Education and Therapy, 6, 11-16, 1980.

WILSON, G. \& RAHMAN, QAZI. Born gay: The psychobiology of sex orientation. London (UK): Peter Owen, 2005. 
WOLKE, D. Playground bullies healthier than victims. Retirado em Outubro, 2sd, 2001 from http://1w11fd.law11.hotmail. msn.com/cg1 ...tart $=295332 \&$ len $=79780 \& \mathrm{msgread}=1 \& \mathrm{mfs}$ $=51,2001$.

ZUCKER, K., WILD, J., BRADLEY, S. \& LOWRY, C. Physical attractiveness of boys with gender identity disorder. Archives of Sexual Behavior, 22, 23-36, 1993.
ZUCKER, K. Gender identity disorders in children: Clinical descriptions and natural history. Em R. Blanchard \& B. Steiner (Orgs.), Clinical management of gender identity disorders in children and adults (pp.1). Washington: American Psychiatric Press, 1990.

Recebido: dez/2008

Aprovado: jun/2009 